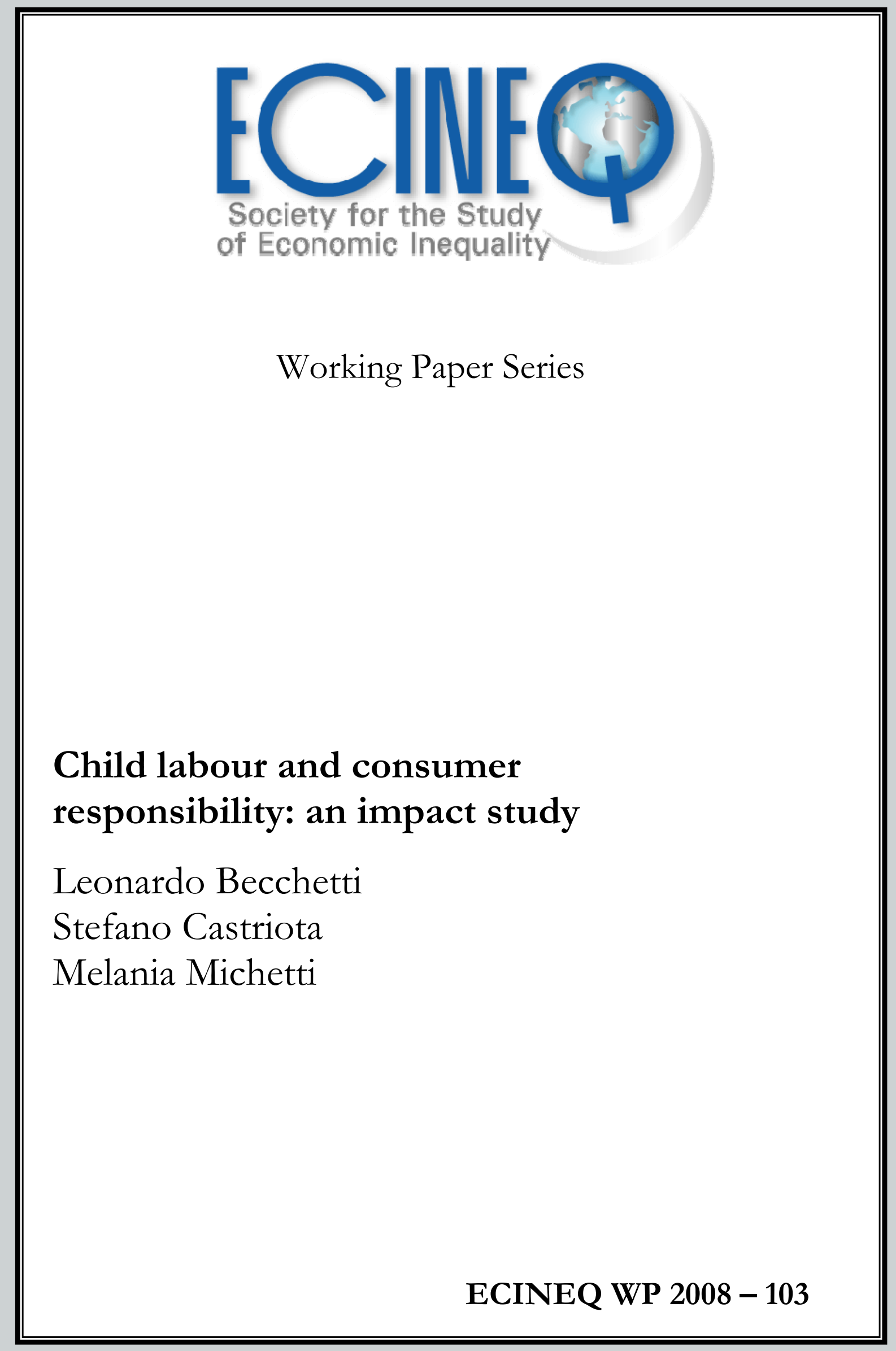


www.ecineq.org

\title{
Child labour and consumer responsibility: an impact study
}

\author{
Leonardo Becchetti ${ }^{\dagger}$ \\ University of Rome Tor Vergata \\ Stefano Castriota \\ University of Trento \\ Melania Michetti \\ Fondazione Eni Enrico Mattei(FEEM)-Università Cattolica Milano
}

\begin{abstract}
We evaluate the impact of fair trade (FT) affiliation on child labour within a sample of Chilean honey producers with a retrospective panel data approach. From a theoretical point of view we argue that, FT generates a short run pure income effect together with a medium run productivity effect, on both adult and child wages. The direction of the impact is therefore uncertain and requires empirical testing. Our econometric findings document a significant impact of affiliation years on child schooling after controlling for endogeneity and heterogeneity between the treatment and control sample.
\end{abstract}

Keywords: Fair Trade, child labor.

JEL Classification: O19, O22, D64.

\footnotetext{
* The author thanks F. Adriani, S. Anderson, M. Bagella, K Basu, F. Bourguignon, R. Cellini, L. Debenedictis, M. Fenoaltea, P. Garella, I. Hasan, L. Lambertini, S. Martin, C. McIntosh, N. Phelps, G. Piga and P. Scaramozzino, M E. Tessitore, P. Wachtel, C. Whilborg, H. White, B. Wydick for the discussion on fair trade issues and all participants in the seminars held at the XV Villa Mondragone Conference, at SOAS in London, at the Copenhagen Business School and the Universities of Catania, Bologna, Macerata and Milano Bicocca, at the 2008 Poverty and Growth NETwork (PEGNET) conference in Accra for the useful comments and suggestions received. The usual disclaimer applies.

† Address of correspondence: Leonardo Becchetti, Facolta di Economia, Dipartimento di Economia e Istituzioni, Via Columbia 2, 00133, Roma. E-Mail : Becchetti@economia.uniroma2.it
} 


\section{Introduction}

The interest of researchers in child labor has proliferated in recent years due to an increase in data availability, the size of the problem, ${ }^{3}$ and the rise of child labour as one of the most politically sensitive issues in our globalised society and in the North-South economic relationships. Even though there is a general consensus on its negative impact on the current and future wellbeing of children, opinions regarding policy measures needed to tackle it, are mixed. On one side, "abolitionists" argue that the best solution is to ban child labour altogether. On the other side, "realists" affirm that its abolition may even be harmful in some contexts and that the ultimate solution to the problem depends on the removal of economic conditions leading to the child labour choice: poor parents are forced to make their children work and would be happy to switch to school as soon as their economic conditions make this choice feasible.

Since child labour is concentrated in less developed countries the child labour controversy ends up having a trade related dimension. A portion of politicians and civil societies in developed countries desume from the "abolitionist approach" that child-made products have to be banned. This measure however, is seen as a trade barrier by developing countries. On the corporate side, the "abolitionist" approach is somewhat consistent with the strategy adopted by "no child labor" labels (such as Rugmark, the international

\footnotetext{
${ }^{3}$ The International Labour Organization recently estimated the number of children engaged in work to be 218 million aged 14 and under (ILO 2006).
} 
nonprofit organization which provides child-labor-free certification), while the "realistic approach" is followed, among others, by the Fair Trade movement. ${ }^{4}$ The objective of our paper is to verify whether the "realistic" approach works by testing the effect of FT affliation on child schooling with field survey data.

More specifically, both Rugmark and Fair Trade (FT) labels aim to sell ethical intangibles to concerned consumers, but their approach is quite the opposite. In the first case we have a "no-child-labor" constraint and no intervention on market prices ${ }^{5}$ while, in the second case, producers are free to choose whether or not to send their children to school but receive a price premium from the organization. Therefore, while Rugmark may realize the goal of reducing child labor directly by banning it in its certified products, FT aims to achieve the same goal indirectly by trying to create a virtuous circle between substitution and luxury axiom (Basu and Van, 1998).

According to the first axiom, the diffusion of child labour may affect the local labour market by depressing adult wages. According to the second, parents send children to school if they overcome a given income threshold. The combination of the two may create a vicious circle where household income below a subsistence threshold triggers child labour and the diffusion of child labour in the area depresses adult wages, thereby making child labour more necessary. Fair Trade, by increasing household income (due to the short term

\footnotetext{
${ }^{4}$ IFAT, the main federation gathering producers and Fair Trade organizations, specifies the criteria that affiliated producers have to follow. One of them claims that the participation of children, if any, should not adversely affect their well-being, security, educational requirements and need for play, and should conform to the UN Convention on the Rights of the Child as well as the law and norms in the local context.

${ }^{5}$ In a recent theoretical model Baland and Duprez (2008) analysing the effects of competition between "child free" and standard products on market prices, outline conditions under which no child labour labels may enhance producers' wellbeing.
} 
price premium and price stability effects and the medium term productivity effect $)^{6}$ may turn the vicious circle into a virtuous one. This occurs if the reduction of child labour in the area, due to the originary income effect, generates a positive effect on adult wages. This last effect reinforces the initial shock thus pushing wages further from the luxury axiom threshold.

A second line of interest when testing the impact of Fair Trade on child education is the comparison of several empirical papers evaluating the effects of conditional cash programs aimed at discouraging child labour by lowering the cost of schooling via educational transfers (Progresa in Mexico, Bolsa Escola in Brazil, Mid-day meals program in India). ${ }^{7}$ These programs have proven to be effective in reducing child labour (Schultz, 2004; Skoufias and Parker, 2001; Schady and Araujo, 2006). However, it is difficult to disentangle the effect of household income from the reduction of schooling cost effects in this literature.

The advantage of our analysis is that Fair Trade generates a pure income effect (albeit from different sources) without any change in the cost of schooling. Another significant difference with respect to these well known programs is that they provide subsidies conditional to the schooling choice, thereby assuming that it is worthwhile to encourage schooling (Baland and

\footnotetext{
${ }^{6}$ These effects should arise from the application of FT criteria. According to IFAT such criteria refer to: i) Creation of opportunities for economically disadvantaged producers; ii) Transparency and accountability; iii) Capacity building; iv)Promoting Fair Trade; v) Payment of a fair price; vi) Gender Equity; vii) Working conditions (healthy working environment for producers); viii) The environment; ix) Trade Relations (Fair Trade Organizations trade with concern for the social, economic and environmental well-being of marginalized small producers and do not maximise profit at their expense. They maintain long-term relationships based on solidarity, trust and mutual respect that contribute to the promotion and growth of Fair Trade. Whenever possible, producers are assisted with access to pre-harvest or pre-production advance payment). For the literature debate on the controversial FT initiative see section 3.

${ }^{7}$ See Edmonds (2007).
} 
Duprez, 2007). Differently, Fair Trade affiliated households have an additional degree of freedom and may decide whether or not to send children to school.

Our empirical analysis falls into a strand of literature which presents mixed evidence on the impact of income on child labour. Most papers find the expected negative nexus (Psacharopoulos, 1995; Cartwright, 1999 and Edmonds, 2005) while others do not register a significant effect (Deb and Rosati, 2002). Ultimately in several theoretical models the income effect may be offset by a substitution effect, when a concurring increase in children wages takes place (Bhalotra and Heady, 2003; Psacharopoulos, 1997).

The goal of our paper is to verify which of these possible relationships is supported by our empirical findings. We do this using evidence collected from a field study in Chile on the Apicoop cooperative working with the FT channel. This paper includes six sections (including introduction and conclusions) and is structured as follows: In the second section we briefly summarize FT characteristics. In the third section we sum up features of the FT-affiliated Apicoop cooperative. In the fourth section we sketch a theoretical model which identifies income and substitution effects of Fair Trade affiliation and provides a framework for the empirical analysis. In the fifth section we describe our sample features. In the sixth and seventh sections we illustrate the econometric methodology and describe econometric findings, discussing our evidence in the light of standard empirical problems of reverse causality, endogeneity and heterogeneity of the treatment and control samples. The ninth section concludes. 


\section{Fair trade}

Fair trade is an economic initiative promoted by importing organizations from Europe and the US and aims to establish long-term relationships with associations of marginalized producers in LDCs in order to promote capacity building, market inclusion and improvement of local wellbeing. Fair Trade criteria include: i) an anticyclical mark-up on producers' prices incorporating an insurance mechanism which prevents them from falling below a certain threshold; ${ }^{8}$ ii) anticipated financing schemes; iii) export services; iv) direct investment in local public goods (health, education) through the contribution provided to the local producers' associations.

More generally, it has been shown that FT criteria may help addressing market failures such as credit rationing, underinvestment in local public goods (health, education, professional training), monopsony of local intermediaries and/or moneylenders (Becchetti and Rosati, 2007). ${ }^{9}$ On the product market side, the success of these products has been shown to generate contagion effects on profit maximising competitors (Becchetti and Solferino, 2008). ${ }^{10}$

The economic debate on Fair Trade revolves around three main critiques. First, it has been observed that the intermediate good price mark-up is a distortion

\footnotetext{
${ }^{8}$ An example of Fair Trade price premium is in the banana market. In Ecuador, the 2005 conventional market price for 1.14 kilos of bananas was 2.91 US \$, against a FT price of 7.75 US \$. Evidence of FT premium on prices of coffee beans and cocoa in the last 20 years is also well known and available from the authors upon request.

${ }^{9}$ For a theoretical evaluation of the effects of FT from the perspective of trade theories see Maseland and De Vaal (2002). Other relevant papers dealing with various aspects of the impact of FT are those of Moore (2004), Hayes (2004) and Redfern and Sneker (2002).

10 Nestlè introduced in October 2005 a fair trade product in its product range, Coop UK launched its own fair trade product line, while Starbucks has rapidly become the main seller of FT coffee in the last few years. For a discussion on competition between fair trade dedicated retailers and supermarkets see also Kohler, 2007.
} 
in respect to the market clearing price, generating excess supply and sending wrong signals to producers. Second, it has been noted that the standard purchase plus charity donation scheme (for an amount equivalent to the price differential between the fair trade and the traditional product) may improve welfare with respect to the fair trade choice (LeClair, 2002). Third, it has been questioned that fair trade may produce negative effects on non affiliated local producers (LeClair, 2002).

On the first point, it can be considered that the ancticyclical price premium may be perfectly consistent with market equilibrium in situations where local intermediaries and moneylenders have monopsony power on marginalised producers. ${ }^{11}$ Beyond this case, it has been considered that the mark-up on the intermediate price, in itself an intangible, creates social and economic value ${ }^{12}$ and makes the final FT product differ from the standard one, converting fair trade to a sort of general purpose innovation which increases product variety. On the second critique, it must be taken into account that charity, dissimilar to the "portfolio vote" of FT consumers, ${ }^{13}$ has no local antitrust effects and does

\footnotetext{
11 This has been verified for Meru Herbs by Becchetti and Costantino (2008) who find that fair trade reduced dependence of affiliated farmers from Nairobi intermediaries and by Becchetti et al. (2008) in a study on affiliated Peruvian wool producers in the Juliaca region (Titicaca lake) where the introduction of fair trade determined an increase in their bargaining power (and an improvement in price conditions) with local intermediaries.

12 Becchetti and Michetti (2008) showed how Fair Trade affiliation may generate significant impacts on a specific type of social capital by reinforcing both social cohesion and generalised trust.

${ }^{13}$ We should conceive FT as the most fashionable example of a more general phenomenon of consumers' revealed social preferences and producers' capacity of extracting surplus from them. Other recent interesting examples are the dedicated shops in Sicily selling products of entrepreneurs who decided not to pay fees to local mafia ("addiopizzo shops") and all the initiatives with which corporations are able to extract the "social surplus" from socially responsible consumers. To quote just few of them, Cathay Pacific adopted a dual pricing policy offering to "concerned" consumers a more expensive air ticket where the price differential with respect to the standard one finances the $\mathrm{CO}_{2}$ reduction policies of the air company; Rabobank, Credit Agricole and other cooperative banks offer to address part of the matured interest on
} 
not create contagion among profit maximising competitors of fair trade. Hence, if we accept that the previous considerations on the beneficial effects of FT on monopoly rents along the value chain are correct, FT is much more powerful than charity in addressing them.

The third critique requires empirical testing. Becchetti et al. (2007) addressed this problem in an impact analysis on the effects of affiliation on two different groups of Peruvian producers. They showed that the externalities on local non affiliated producers resulted positive in one case and negative in a second case.

Based on the above mentioned debate we argue that Fair trade is a new emerging phenomenon which deserves adequate empirical investigation, for at least three additional reasons.

First, FT practice is growing more rapidly than the capacity of economists interpreting the phenomenon. Consumer class is growing very fast, and both socially and environmentally responsible consumption is becoming more and more fashionable in the US and in Europe. Concerned consumers pay attention not only to prices and quality, but also add social and environmental considerations to purchased goods. In this sense, the consumer choices embody opportunities to support sustainable development.

On September the $3^{\text {rd }} 2008$, Ebay launched a dedicated platform (WorldOfGood.com) for fair trade e-commerce. It calculates that the U.S. market for such goods was $\$ 209$ billion in 2005 , and foreacasts that it will rise only by clients or by clients and the bank). 
up to $\$ 420$ billion in 2010 . The little available data suggests that this fashion turned into significant shares in some market segments (47 percent of bananas in Switzerland and 20 percent of ground coffee in the UK), with consumers' willingness to pay for social and environmental responsibility revealed in different surveys around Europe - over and above these figures (Bird and Hughes, 1997; Demos and PI/Coop, 2004; De Pelsmacker et al., 2003). ${ }^{14}$

Second, a serious problem in this field is that social and environmentally friendly characteristics of the products are not an experienced good. Hence, well grounded empirical work is needed to bridge informational asymmetries between buyers and sellers and to evaluate whether FT promises are met or not.

Third, FT impact analyses may verify the application of FT criteria and contribute to their redefinition.

In actual fact, the FT impact study literature mainly consists of some well structured case studies (Bacon, 2005; Pariente, 2000; Castro, 2001; Nelson and Galvez, 2000; Ronchi, 2002; Yanchus and de Vanssay, 2003) and a few econometric impact analyses (Ruben, 2008). Ronchi (2006) finds on a panel based on 157 mill data that FT helped affiliated Costa Rican coffee producers to increase their market power. The author concludes that FT benefits are of a vertical integration type and that "the decision to support fair trade requires other information about its costs and benefits". In an econometric study on the

\footnotetext{
${ }^{14}$ It is commonly known that from the contingent claim literature, virtual willingness to pay generally tends to be higher than the revealed one (Diamond and Hausman, 1994). In our specific case we add that the virtual choice between a FT and a standard product is easier than the real life choice, due to the differences in search costs for the two types of products and asymmetric information of interviewed consumers about the ethical characteristics of the FT product.
} 
impact of FT on Kenyan farmers, Becchetti and Costantino (2008) show that capacity bulding, trade and product risk diversification (an element not included in official criteria), which reduces their vulnerability to shocks, are the main sources of benefit for local affiliated producers. An empirical analysis on Peruvian producers (Becchetti et al., 2007) finds that affiliation has significant effects on professional self esteem and life satisfaction (also not considered among FT criteria).

The specific goal of our study is to analyse the effects of FT affiliation on child schooling by creating economic opportunities for poor producers. Moreover, as mentioned previously, FT may help in addressing market failures such as credit rationing by providing members with various advantages such as interest-free credit support, anticipated financial schemes, an anticyclical mark-up on producers' prices which incorporates an insurance mechanism, and product risk diversification ${ }^{15}$ which lower the producers' vulnerability to shocks (Becchetti and Costantino, 2008). The theoretical and empirical literature supports the importance of access to the credit market and the containment of shocks in determining the household decisions concerning children's time allocation. ${ }^{16}$ The imperfections of credit and insurance markets, both formal and informal represent, particularly in developing countries, a very relevant point in the allocation of household resources to human capital investments that are often suboptimal.

\footnotetext{
${ }^{15}$ Good markets may also influence child labour through their relative return to child time (Edmonds, 2007).

16 Different empirical studies show the relevance of access to credit markets and of containment of shocks in determining children's labor supply. See, among others, Ranjan (2001), Cigno, Rosati, and Tzannatos (2002), Guarcello, Mealli and Rosati (2002).
} 
Our empirical analysis aims at verifying whether FT strategy is successful in the specific case of a cooperative (Apicoop) of Chilean FT affiliated honey producers.

\section{Apicoop}

Apicoop is a Fair Trade organization based in Paillaco, a village close to Valdivia in the region of Los Lagos in Chile, around $900 \mathrm{~km}$ south of the capital Santiago. Its history traces back to the 70 s when the economic situation during the dictatorship was very difficult and the Church tried to promote development programs through the Diocese. As a consequence, in 1978 the Diocese Valdivia funded Fundesval (FUNdación DESarrollo VALdivia) with capital coming from Western European donations. Fundesval was composed of six programs, one of which was related to the production of honey. The targets of the honey project were to create an additional source of income to farmers, create a cooperative where people could share knowledge and technology and improve the diet of the population through the consumption of honey.

The only profitable program was the honey production project, while the remaining five programs were losing money and were finally closed in 1998, when the Diocese accepted the honey producers' request to let them become independent and take over the cooperative in exchange of 1800002008 USD. After the purchase of the cooperative, farmers invested a significant amount of money to realize technical improvements, increase total production and productivity per bee-hive and achieve financial independence. Over the last decade Apicoop has expanded its production considerably and has become the 
fourth Chilean exporter of honey and the first Chilean producer of Fair Trade honey. Nowadays the association is composed of 127 partners, 123 of whom are individuals, and 4 cooperatives, concentrated mostly in the Los Lagos region.

Apicoop members benefit from the commercialization of honey through the cooperative and receive free technical assistance and interest-free credit support. Furthermore, FT associations provide contracts with longer prospects which in turn, reduce the variation of revenues and profits ${ }^{17}$. All these valuable services have helped farmers to increase their production level and quality over time.

\section{The theoretical framework}

In order to sketch the potential effect of Fair Trade affiliation we start from the simplified Edmonds (2007) model in which the arguments of the household utility function $U\left(S, V_{k}\right)$ are family wellbeing $(S)$ and children's future wellbeing $\left(V_{k}\right)$. We assume as usual that $U^{\prime}()>$.0 and $U^{\prime \prime}()<$.0 .

Family wellbeing is in turn specified as a linear, homogeneous production function: $S=F(c, H)$

Where $(S)$ depends on purchased inputs $(c)$ and hours that a child works inside the household $(H)$.

\footnotetext{
17 In the period 2002-2004, for example, there has been a sudden rise in the honey price because of an antibiotic scandal which led the EU to ban the Chinese and Argentinean honey for two years. In 2005, once imports from China and Argentina were restarted, the price fell by more than $40 \%$. Large fluctuations in honey prices like these can severely compromise the producer's loan repayment schedule.
} 
Children's wellbeing, $V_{k}=R(E, P)$, is, in turn, a function of education $(E)$, and leisure and play $(P) .{ }^{18}$

The household faces the following budget constraint:

$c=Y+w M-e E$

Where $(Y)$ is a parent's exogenous income, $(w)$ is a child's exogenous wage, $(M)$ is hours worked by the child, with $(e)$ and $(E)$ being the direct costs and the hours of child education respectively.

As a consequence, parents maximise the following function:

$$
\underset{M, E, P, H}{\operatorname{Max}} u[F(Y+w M-e E, H) ; R(E, P)]
$$

Subject to: $E+P+M+H=1 ; E \geq 0 ; P \geq 0 ; M \geq 0 ; H \geq 0$

Moreover, if child is engaged in wage work, parents decide not to send him to school if

$$
\frac{\partial u}{\partial V_{k}} \frac{\partial R}{\partial E}-\frac{\partial u}{\partial S} \frac{\partial F}{\partial c}(e+w) \leq \lambda
$$

That is, the marginal increase in the utility of parents (because of the higher children's future wellbeing due to education) minus the marginal reduction in family wellbeing (due to the cost of education) is lower than or equal to the marginal utility of time. Although Fair Trade does not ban child labour, it may have some effects on its reduction due to the short run pure income effect 
generated by the price premium applied on the commercialised honey. Since child labour is not banned, both adult and child labor incomes ${ }^{19}$ may rise. Assuming that $Y$ represents the total amount of incomes from different sources, the condition (2) therefore turns into:

$$
\frac{\partial u}{\partial V_{k}} \frac{\partial R}{\partial E}-\frac{\partial u}{\partial S} \frac{\partial F}{\partial c_{1}}(e+w+\Delta w) \leq \lambda
$$

Where $c<c_{1}=(Y+\Delta Y)+(w+\Delta w) M-e E$

The second term of the inequality has a first part which is now smaller, due to the concavity of the utility function. In other terms, at a higher family income level, the loss of family wellbeing due to the cost of education hits less. On the other hand, the second part of the second term is bigger since the opportunity cost of child education has increased because of the price premium. The effect of Fair Trade on child labour is therefore ambiguous and depends on the relative size of the first and the second part. Consider, however, that most empirical studies, including that of Becchetti and Castriota (2008) on the same Chilean sample of honey producers, emphasize that, in the medium run, affiliation years progressively increase productivity and in turn the income of affiliated producers vis-à-vis the control sample of producers working in the same area. ${ }^{20}$ To take into account the medium run effect of Fair Trade we should rewrite $\left(2^{\prime}\right)$ as

\footnotetext{
${ }^{19}$ If the child also works for FT certified products.

20 The authors find that affiliation years have positive effect on honey sold per hour worked, net of the economies of scale effect to which also FT contributes. The main candidate for this
} 
$\frac{\partial u}{\partial V_{k}} \frac{\partial R}{\partial E} \pi-\frac{\partial u}{\partial F} \frac{\partial F}{\partial c_{2}}\left[e \pi+\left(w+\Delta w \tau_{c}\right)(\rho \mid \varphi)\right] \leq \lambda$

Where $c<c_{1}<c_{2}=\left(Y+\Delta Y \tau_{a}\right)+\left(w+\Delta w \tau_{c}\right) M(\rho \mid \varphi)-e E \pi$

with $\tau_{a}$ and $\tau_{c}$ being respectively the medium run productivity multiplier on adult income and child wages, $\rho$ the probability that the child will still work over the medium term and $\varphi$ the probability that he will continue to do the same job.

There are three differences between short and medium run effects. In the medium term, higher productivity increases both adult income and child labour income, more so than in the short run, and it has effects on children's future wellbeing from education (assuming that the child will do the same job with probability $\varphi$ ). We have therefore, two positive effects against a negative one in terms of reduction in child labour.

If the latter is smaller, the medium run effect of FT in terms of child labour reduction should be positive and larger than in the short run effect and any affiliation year would generate an additional positive effect on schooling.

\section{Descriptive findings}

Evidence presented in the following sections derives from 234 honey producers, randomly sampled from two previously created treatment and 
control group sets containing farmers affiliated and not affiliated to Apicoop respectively.

FT has existed in the area for many years, making it impossible to create a randomised experiment to analyse its impact. However in the following section, we show a methodology and a series of robustness checks which make us quite confident that the selection bias problem does not invalidate our findings. What we already anticipate is that the availability of a graduated exposition to the treatment (different years of affiliation) allows us to perform robustness check estimates only on the treatment group, thereby reducing many of the problems related to the heterogeneity between treatment and control group individuals.

Producers were interviewed in February and March 2008. The questionnaire consisted of a set of standard questions on socio-demographic and economic variables, plus other questions related specifically to honey production. Table 1 describes the variables considered in this study while Table 2 illustrates their summary statistics for the whole sample of affiliated (Flo) and non-affiliated (no Flo) producers.

The majority of interviewed producers are male, middle-aged, with elementary or intermediate education (although there are some people with no formal education). On average, around 42 percent of the total farmers' income comes from honey, an additional 7 percent from other activities connected to bees while the remaining 51 percent comes from agriculture, breeding and other activities. Honey and other products from bees play a crucial role for these families. The average production of honey is $3,000 \mathrm{~kg}$, but the second quartile 
is only $1,000 \mathrm{~kg}$. Therefore, the majority of the sample is composed of small producers. The average productivity of honey per hour of work devoted to this activity is $180 \mathrm{~kg}$, with notable dispersion due to experience, capital accumulated, and the technology adopted.

Becchetti and Castriota (2008), using treatment regression and Peer Matching models, find that the higher productivity of Apicoop's producers is partially explained by their superior capacity to exploit economies of scale. The lack of time series data prevents them from fully disentangling the productivity effect due to selection bias, from that attributable to FT affiliation. However, Apicoop's producers receive more training courses and advances of payments than independent ones. It suggests that affiliation contributed both to, and independently from, the economies of scale effect.

In our study it is necessary to avoid omitted variable biases by considering all relevant factors affecting child schooling. Again from Table 2 we can see that the number of producers' school years is twice that of their parents: there is a clear advancement in the average level of education due to the improving economic conditions of the country as a whole, which is a worldwide trend common in both rich and poor countries.

A second important observation regarding education is the existence of a large number of producers with recent affiliation. More than a third, 36.15 percent, have less than 4 years of affiliation while 50 percent have less than 6 years (see Table 3). Figure 1 shows the education level of the producer and his parents by the number of affiliation years, averaged over the period 20012007. The higher the FT age is, the lower the average level of education. 
Table 4 shows the average education levels by year and by subgroup of FT age for the producer and his parents. Looking at each column we can see that the education level of new FT members is higher than that of older members, while, looking at table rows, we can see the increase of the level of education over time. The same relationship is confirmed if we replace the producer's education with the schooling years of his parents. ${ }^{21}$

Specifications of econometric estimates which follow will take into account the descriptive results: i) by considering the increasing trend of scholarisation we introduce year dummies in our econometric estimates. Given the prevalence of producers with a limited number of affiliation years, omission of year effects would probably determine a downward bias on the effect of affiliation years on child schooling; ii) by considering the strong negative correlation between years of affiliation and the producers' education we introduce fixed effects. The omission of fixed effects (which can capture, among other time invariant components, the education level of the producer and of his parents) could again, downward bias the effect of affiliation on child schooling, given the expected positive relationship between education and the decision to send children to school.

\section{Econometric approach}

An important problem in development studies is how to reconcile the need of inferring causal relationships with the difficulty of performing repeated surveys (especially in situations where attrition problems may be difficult to

\footnotetext{
${ }^{21}$ The only exception is the education of the producer's mother for affiliation year cohort 10-12 which can be attributed to some noise given the reduced number of observations considered in the considered subsample.
} 
overcome). In this paper we propose a "backcast panel" approach which allows us to reconstruct panel data from a unique cross-sectional survey. More specifically, we ask each producer the number of his/her offspring and the age and number of schooling years for each of them. To complete our information, we also ask producers the age at which each child started school and whether there were cases of exits and re-entries.

As commonly recognised, we should rely on answers regarding recent past events, so that they are not too difficult to recall. Consider also, that standard cross-sectional surveys data require a certain degree of memory from the respondents (after all, all questions refer to past events, even though they occurred in the same or previous year). In this respect we reasonably argue that it is not difficult for a parent to remember an important part of their children's past such as the number of their schooling years. ${ }^{22}$ With this information we can reconstruct, year by year (from 1987 to 2007), schooling decisions taken by the household. After that we are able to regress the schooling decisions on fixed effects which incorporate the impact of a set of controls that are time invariant during the panel period, ${ }^{23}$ and on factors where variation can be reconstructed without information collected in the years before the survey ${ }^{24}$. Note that in this way we rely on a small set of easily defined variables where measurement error problems should be relatively limited.

\footnotetext{
${ }^{22}$ On the methodology for the construction of retrospective panel data with memorable events see also McIntosh, Villaran, and Wydick (2007).

${ }^{23}$ Including gender, schooling years of the producer and of the producer's parents

24 Those are Age, participation to the treatment or to the control sample, FT affiliation years, number of children in the school age cohort.
} 
Once we have constructed the database we can calculate a time varying index of human capital investment for each producer, represented by the number of children attending school over the total number of children in the schooling age cohort in the given year. More formally, the household schooling investment ratio (HSI) is given by the following expression:

$$
H S I_{i t}=\sum_{j=1}^{n_{i}} \frac{\text { TOTSCH }_{i j t} \mid \text { Entryage }_{i j t} \leq \text { Age }_{i j t} \leq \text { Endage }_{i j t}}{i j t \mid \text { Entryage }_{i j t} \leq \text { Age }_{i j t} \leq \text { Endage }_{i j t}}
$$

where the HSI it index is composed of the number of the $\mathrm{j}$ children of the $\mathrm{i}$-th producer in a chosen school age cohort (e.g. age range between $6^{25}$ and 18 , if we are interested in elementary, middle and high school, and between 13 and 18 if we are only interested in high school, etc.) who actually went to school in a given year $\mathrm{t}\left(\right.$ TOTSCH$\left._{i j t}\right)$, divided by the number of children of the $\mathrm{i}$-th producer being in the school age cohort in the same period $\left(\right.$ TOTPOT $\left._{i j t}\right) .{ }^{26} \mathrm{In}$ other words, the $\mathrm{HSI}_{\mathrm{it}}$ index is a ratio of effective to potential household school attendance. In our first exercise the dependent variable is regressed on various controls in a fixed effect model with the following specification:

$$
H S I_{i t}=\alpha_{0}+\alpha_{1} \text { Age }_{i t}+\alpha_{2} \text { TOTPOT }_{i t}+\alpha_{3} \text { FTage }_{i t}+\sum_{k} \beta_{k} \text { Dtime }_{k}+u_{i}+\varepsilon_{i, t}
$$

\footnotetext{
${ }^{25}$ Entry age is generally 5 or 6 and is based on the respondent declaration.

${ }^{26}$ The total number of children for each farmer $\left(n_{i}\right)$ is indexed to account for heterogeneity in household size.
} 
where $\left(\mathrm{Age}_{i t}\right)$ is the age of the i-th producer at time $t$, (TOTPOT ${ }_{\text {it }}$ ) is the denominator of the schooling index or the number of children for the selected school age cohort in a given year, $\left(\mathrm{FTage}_{\mathrm{it}}\right.$ ) are years of FT affiliation, (Dtime $\mathrm{t}_{\mathrm{t}}$ are year dummies and $u_{i}$ is the producer specific intercept typical of fixed effect models. The effect of other variables such as gender and respondent schooling years are captured by fixed effects which also capture other non measurable individual time invariant characteristics.

A traditional problem which may not be fully overcome in our estimates is the omission of current income. If it is true that this omission may generate an upward bias on the affiliation coefficient, it is also true that, as far as affiliation has positive effects on income, as shown in previous estimates, (see Becchetti and Castriota, 2008) part of the positive effect of income on schooling should be attributed to Fair Trade. Consider also that factors incorporated into the fixed effects, such as schooling years and age cohort, are generally accepted as proxies of this unobserved variable. Starting from this fixed effect specification, we will move to different approaches in order to face the main issues arising from our empirical analysis: heterogeneity between the treatment and control groups, reverse causation, endogeneity, omitted variable bias.

\section{Empirical findings: dealing with heterogeneity between treatment and control samples}

In table 5.1 we present results from fixed effect estimates in which the dependent variable differs according to the considered school age cohort (from 
$10-18$ and from $14-18$, age ranges). We find that the affiliation year variable is always significant and positive. The magnitude of the coefficients tells us that one additional year of affiliation raises the schooling index within the 14-18 age range by around 1.8 percent. The FT effects are stronger in the high school age cohort and are gradually reduced downward (in regards to the 1018 interval one year of FT affiliation has a positive impact of .9 percent on the schooling index). The total number of children in the considered school age interval for a given year (TOTPOT) is negative and becomes significant in the last three equations (from 12-18 and from $10-18$, age ranges). The sign is reasonable since, the higher the number of children sent to school, the larger the total cost of education for the household.

An interesting point to have emerged is related to the producer's age which is always negative and strongly significant, with a coefficient magnitude between .2 and .3. This implies that, net of the year effects capturing country level changes, and net of the parents' education years absorbed in the fixed effects, the older the father the lower the child schooling index. This variable could capture the progressively reduced working ability of the father which increases the opportunity cost of sending children to school.

Finally, coefficients of the different year dummies clearly evidence a progressive trend toward increased human capital investment at country level (to which the dynamics of domestic GDP growth must have contributed). This is consistent with evidence shown in Figure 1 on respondents and the schooling years of their parents. The lack of consideration of this phenomenon would have downward biased the effect of FT affiliation, since there is a large 
share of recently affiliatiated producers (Table 2) and, who are therefore, more likely to send their children to school.

On the other hand, the introduction of fixed effects marks another downward bias of the impact of affiliation on schooling. As shown in the previous section, and also due to the progressive tightening of cooperative entry standards, more recently affiliated producers tend to have higher education and, for this reason, they are expected to be more likely to send their children to school.

We are aware that an important missing variable in our estimate is the dynamics of household income across estimation years. This is a typical problem in child schooling estimates. Literature usually accepts that this missing variable is proxied by household education and by the producer's age. The inclusion in our specification of the total number of children in the schooling age cohort in the year of interest, should also help because it captures an effect which reduces household income available for the education of any individual child.

One potential limit of our approach lies in the heterogeneity between the treatment and control sample. It has, in fact, been observed that problems in the definition of the control sample may introduce systematic biases between control and treatment observations which may affect the validity of the empirical findings. A Heterogeneity problem may apply to our analysis where we have a situation of non random placement in the program (the decision to affiliate to FT is not random but depends on a decision taken in the past by the observed producers). 
As an extreme solution to this problem we re-estimate our model by excluding observations from the control sample. This is possible since, contrary to many cases in which the treatment effect can just be measured by a (0/1) dummy, we have a measure of the graduation or intensity of the treatment (number of affiliation years).

A primary variation with respect to what is shown in Table 5.1, is that the magnitude of the affiliation year coefficient is larger, by around 4 percent (Table 5.2). However, the first two coefficients are significant at 90 percent and the standard deviation of the coefficient is much higher. The overlap of confidence intervals leads us to conclude that the difference in magnitude between coefficients in Table 5.1 and 5.2 is not significant. A secondary variation is that the variable measuring the total number of children in the given school age cohort is no longer significant. This implies that, within cooperative members, the negative effect of a higher number of children in education hits less than in the overall sample.

At this point of the analysis we wonder why affiliation years increase child schooling. We have two main interpretations for this effect. First, affiliation raises household income by increasing productivity in more affiliated producers, vis-à-vis the control sample. This was also found on the same sample by Becchetti et al. (2008), where the affiliation seems to help producers exploit economies of scale and get closer to the optimal productive dimension. They also find that the positive affiliation effect on productivity may be explained by three factors offered by the cooperative (training, cooperation and advances on payments) (see footnote 8 ). 
However, an alternative interpretation is that cooperative rules and its attention toward child schooling play an important role in determining this result. ${ }^{27}$ Unfortunately, it is not possible to discriminate between these two interpretations with the available information.

\section{Reverse causality and endogeneity: a GMM approach}

Do our results suggest that FT affiliation positively affects child schooling or should we interpret them in the reverse way? It is, in fact possible that explicit selection criteria admit producers into the cooperative, only with higher education and who are more willing to send their children to school. It is also possible that affiliation is driven by an unobservable such as entrepreneurial ability (implicit selection) which is, in turn, correlated with income and child schooling decisions.

An initial argument against reverse causality is the observation of the positive effect of any additional affiliation year on child schooling. The reverse causality link is mostly a once-for-all effect. If it were the only one to work, there would be less reason to expect that the positive relationship between $\mathrm{FT}$ and schooling years progresses with affiliation seniority. This specific finding (even though it cannot exclude the joint presence of a reverse causation once-for-all effect too) further suggests that there is something which can be acquired through the affiliation experience which promotes child schooling. Furthermore, our previous result on the absence of a significant difference

\footnotetext{
${ }^{27}$ Even though, as we remember, FT does not impose a ban on child labor, it has the explicit goal of improving gradually children wellbeing and therefore promotes their education when the household has sufficient income to afford it.
} 
between affiliated pre-affiliation trends and control sample trends in child schooling rules out other possible forms of endogeneity.

A second argument comes from the observation of the Apicoop history. Entry requirements have become progressively stricter so that, if a selection bias exists, it should act in the opposite way and offset the potential impact of affiliation years on productivity. In 2006 this was made explicit in the statute of Apicoop, which now establishes a set of requisites in order to be accepted. The most important of them states that the applicant must have at least 3 years of proven honey production and at least 25 beehives. The progressively more severe affiliation criteria are consistent with what we found in our descriptive findings. We clearly illustrated how a "vintage" factor such as a producer's scholarisation (invariant from the first affiliation year to now) which should be correlated with productive skills, gets larger over time (see Figure $1)$.

We do, however, want to tackle the casuality and endogeneity problem with a quantitative approach, re-estimating the model in a dynamic panel specification. The new specification is

$$
\left.H S I\left(\tau_{k}, \tau_{l}\right)_{i, t}=\alpha_{0}+\alpha_{1} \operatorname{HSI}\left(\tau_{k}, \tau_{l}\right)_{i, t-1}+\alpha_{2} \operatorname{Ag} e_{i, t-1}+\alpha_{3} \operatorname{Totpot} \tau_{k}, \tau_{l}\right)_{i, t-1}+\alpha_{4} \operatorname{Ftag}_{i, t-1}+\sum_{k} \beta_{k} \operatorname{Dtime} e_{k}+\varepsilon_{i, t}(5)
$$

where $\operatorname{HSI}\left(\tau_{k}, \tau_{l}\right)_{i, t}$ is the schooling investment index for the $\left(\tau_{k}, \tau_{l}\right)$ school age cohort, Totpot $\left(\tau_{k}, \tau_{l}\right)$ is the total number of a producer's children in the school age cohort when considering the age interval and the other variables as defined in (4). 
The specification presented in (4) contains lagged values of the dependent variable among regressors. Arellano and Bover (1995) together with Blundell and Bond (1998) demonstrate that the correlation between the lagged dependent variable and the error term makes OLS estimates biased and inconsistent, even when error terms are not serially correlated.

They develop a GMM approach to tackle this issue and as in the GMM way, we identify a set of endogenous or predetermined, and a set of strictly exogenous, instruments. In the first case we chose the education of the producer and of the producer's parents. In the second one we chose two and three period lagged values of affiliation years plus year dummies.

In order to estimate Euler equations in our paper we follow the system GMM approach with two-step estimates of regressors' coefficients. We use robust two-step estimates with the Windmeijer (2005) finite sample correction which has been shown to reduce the bias of excessively low standard errors in twostep estimates.

Diagnostics on these estimates show that residuals are first order, but not second order, autocorrelated, consistently with one of the base assumptions required for a GMM estimate (Table 6.2). The Sargan test does not reject the null hypothesis of the overall validity of the instruments we use in our estimates. The null of exogeneity of our strictly exogenous instruments (two and three period lagged values of affiliation years plus time dummies) is not rejected by the Davidson-McKinnon test.

Signs are those expected and confirm results from fixed effect specification: producer's age is negative and significant, producer's education, which was 
previously absorbed in the fixed effects, is now negative and significant as expected. The Totpot variable is not significant. A likely interpretation is that its effect is entirely absorbed by the lagged dependent variable. The magnitude of the positive and significant affiliation year effect is now around 1.5 percent, very close to the values found in fixed effect estimates.

As a further check on our findings we consider that our results might also be explained by a significant difference in pre-affiliation trends (hence heterogeneity between the treatment and control sample and where FT benefits would not be the driver of the affiliation effect). We therefore add to Table 6.2 , a test on the assumption of common pre-existing trends between treatment and control producers. More specifically, we re-estimate the model in the subsample of observations of control and treatment producers before FT affiliation. Furthermore, with respect to the standard specification we replace the Ftage variable with a trend variable multiplied by a dummy which picks up future affiliated producers. The interaction variable is never significant in supporting the hypothesis of common preaffiliation trends between treatment and control producers.

An even more drastic solution to the problem of heterogeneity between the treatment and control sample is, as in the case of fixed effects, the reestimation of the model with observations from the treatment sample only to eliminate the problem of heterogeneity between the treatment and control samples. We find that the effects of affiliation years remain robust and the diagnostics of the GMM estimates are substantially unchanged (Table 6.3). 
We apply the same reasoning to preaffiliation trends on the estimate restricted to the treatment sample. Alternatively, an observationally equivalent explanation of our findings here could be heterogeneity between older and younger affiliated producers, with the former having steeper trend effects on the dependent variable with respect to the latter. In this case the positive $\mathrm{Ft}$ age coefficient would not depend on FT affiliation benefits but would just reflect heterogeneity among different affiliation cohorts. Again, we restrict the treatment sample estimate to the preaffiliation period and create two additional variables: a linear trend multiplied for a (0/1) dummy for producers with less than 5 years of affiliation and the same linear trend multiplied for a $(0 / 1)$ dummy for producers with more than 10 years of affiliation. Coefficients and standard errors of the two variables, shown in Table 6.3, reject the assumption of significant preaffiliation trends.

\section{Conclusions}

Our paper aims to test the effect of a relatively rarely explored approach to improve the wellbeing of marginalized producers (Fair Trade) with original field data and an innovative methodological approach.

The originality of the FT strategy is that it does not directly impose restrictions on child labour but tries to reduce it indirectly, by promoting short (price premia) and long (capacity building) run increases in a producer's household income.

We try to overcome the difficulty of building panel data with surveys repeated over time in field development studies by using backcast panel data 
methodology. This reconstructs retrospectively "memorable" past values of relevant variables based on cross-sectional information collected in a single survey.

This approach asks respondents to reconstruct some essential traits of the schooling records of their children (year of entry and year of exit). Its success and minimization of measurement error depends on the fact that very few memorable events in the past are referred to (it is hard to imagine that a parent does not remember the scholarisation level of his/her children).

Our empirical analysis is framed in a very simple theoretical approach. From first order conditions of a standard problem of maximization of a household who cares about its own and its children's present and future wellbeing, we observe that FT affiliation may generate income and substitution effects. The direction of the total effect is therefore unclear and needs to be tested empirically.

In the econometric part of the paper we start by carefully reflecting on the consequences of omitted variable biases. In this respect, with fixed and year effects we demonstrate how to avoid two potentially omitted variable problems in our survey (negative correlation between affiliation year and producer's education and a relatively larger number of producers with a small amount of affiliation years).

We also carefully examine whether the observed positive and significant relationship between affiliation years and child schooling may be affected by problems of heterogeneity between the treatment and control sample, reverse causality and endogeneity. 
Robustness checks of estimates restricted to the treatment group, dynamic GMM regressions with proper predetermined and strictly exogenous instruments, tests on common preaffiliation trends (between treatment and control producers and between young and old affiliated) and the history of the cooperative admission criteria make us confident that our findings are robust.

\section{Rerences}

Arellano, M., and O. Bover, (1995); Another look at the instrumental variables estimation of error components models. Journal of Econometrics 68: 29-51

Bacon, C. (2005). Confronting the Coffee Crisis: Can Fair Trade, Organic, and Specialty CoffeesReduce Small-Scale Farmer Vulnerability in Northern Nicaragua? World Development 33(3), 497-511.

Basu K. and Van P.H., (1998); The Economics of Child Labor. American Economic Review 88:412-427.

Baland, J.M. and Duprez, C. (2008); Are Fair Trade Labels Effective Against Child Labour? CEPR Discussion Paper No 6259.

Becchetti L., Castriota S., Michetti M., (2008); Testing the luxury axiom: the effects of fair trade on child schooling decision on a sample of Chilean honey producers, mimeo.

Becchetti, L. Giallonardo E. Tessitore, N. (2008); Ethical product differentiation with symmetric costs of ethical distance. Rivista di Politica Economica, forth.

Becchetti L., Costantino M. (2008); Fair Trade on marginalized producers: an impact analysis on Kenyan farmers. World Development 365: 823-842. 
Becchetti L., Michetti, M., (2008); When Consumption Generates Social Capital: Creating Room for Manoeuvre for Pro-Poor Policies. Ecineq working papers 88.

Becchetti L., Solferino, N. (2008). On ethical product differentiation, Economia e Politica Industriale, (forth).

Becchetti L., Rosati F. (2007); Globalisation and the death of distance in social preferences and inequity aversion: empirical evidence from a pilot study on fair trade consumers, The World Economy, 30 (5): 807-30.

Becchetti L. Costantino M. Portale E., 2007, Human capital, externalities and tourism: three unexplored sides of the impact of FT affiliation on primary producers, CEIS working paper n. 262

Bhalotra, S., Heady, C. (2003); Child Farm Labor: The Wealth Paradox. World Bank Economic Review 17(2): 197-227.

Blundell, R., Bond S. (1998); Initial conditions and moment restrictions in dynamic panel data models. Journal of Econometrics 87: 11,143.

Castro, J.E. (2001); Impact assessment of Oxfam's fair trade activities. The case of Productores de miel Flor de Campanilla. Oxford: Oxfam.

Cartwright, K. (1999); Child Labor in Colombia. In The Policy Analysis of Child Labor, A Comparative Study, edited by Grootaert C. and Patrinos H. A., Washington D.C., World Bank.

Cigno, A., Rosati, F. (2005). The Economics of Child Labour. (Oxford University Press, Cambridge).

Cigno, A., Rosati, F. and Z. Tzannatos (2002), Child Labor Handbook. WB Social Protection Discussion Paper N. 0206.

Davidson, R. and MacKinnon, J. (1993); Estimation and Inference in Econometrics. New York: Oxford University Press.

Deb, P. and Rosati, F. (2002); Determinants of Child Labor and Scholl Attendance: The Role of Household Unobservables. Understanding Childrens Work Working Paper. Florence: Innocenti Research Center.

Diamond, P., Hausman, J., (1994); Contingent Valuation: Is Some Number Better than No Number? Journal of Economic Perspectives, 8: 45-64.

Edmonds, E. V. (2005); Does child labor decline with improving economic status? The Journal of Human Resources 40: 77-99.

Edmonds, E. V., (2007); Child labor. NBER Working Paper n. 12926 
Guarcello L., Mealli F., Rosati F. (2002). Household Vulnerability and Child Labour: the Effect of Shocks, Credit Rationing and Insurance. UCW Working Paper 3, Understanding Children's Work (UCW Project).

Kohler P. (2007); The Economics of Fair Trade: For Whose Benefit? An Investigation into the Limits of Fair Trade as a Development Tool and the Risk of Clean-Washing.06-2007, HEI Working Papers.

Hayes, M. (2004); Strategic management implication of the ethical consumer. <http://www.fairtraderesearch.org>.

ILO (2006); The End of Child Labour: Within Reach. Geneva.

Leclair, M. S. (2002); Fighting the tide: Alternative trade organizations in the era of global free trade. World Development 30(7): 1099-1122.

Maseland, R., \& De Vaal, A. (2002); How Fair is Fair Trade? De Economist 150(3): 251-272.

McIntosh, C., Villaran, G. and Wydick, B. (2007); Microfinance and Home Improvement: Using Retrospective Panel Data to Measure Program Effects on Fundamental Events. University of San Francisco Departmental Working Paper.

Moore, G. (2004); The Fair Trade Movement: parameters, issues and future research. Journal of Business Ethics 53(1-2): 73-86

Nelson, V. \& Galvez, M. (2000); Social Impact of Ethical and Conventional Cocoa Trading on Forest-Dependent People in Ecuador. University of Greenwich.

Pariente, W. (2000); The impact of fair trade on a coffee cooperative in Costa Rica. A producers behaviour approach. Université Paris I Panthéon Sorbonne, No 1161-98, University of Wisconsin.

Psacharopoulos G., Patrinos H. (1995); Educational Performance and Child Labor in Paraguay. International Journal of Educational Development, 15(1): 47-60.

Psacharopoulos G. (1997); Child Labor Versus Educational Attainment: Some Evidence from Latin America. Journal of Population Economics, 10(4): 377386.

Ranjan, P. (2001), Credit Constraints and the Phenomenon of Child Labor. Journal of Development Economics, LXIV, 81-102.

Redfern, A. \& Snedker, P. (2002); Creating market opportunities for small enterprises: experiences of the fair trade movement. ILO, Geneva. 
Ronchi, L. (2006); "Fairtrade" and Market Failures in Agricultural Commodity Markets. World Bank Policy Research Working Paper 4011. Washington: IBRD.

Ronchi, L. (2002); The impact of fair trade on producers and their organizations: a case study with Coocafè in Costa Rica. University of Sussex.

Ruben, R., (2008); The impact of fair trade. Wageningen Academic Publishers, Wageningen.

Schady, N. and M., Araujo (2006); Cash transfers, conditions, school enrollment, and child work: Evidence from a randomized experiment in Ecuador. Policy Research Working Paper no. 3930 (The World Bank, Washington, D.C.).

Schultz, T. (2004); School subsidies for the poor: Evaluating the Mexican progresa poverty Program. Journal of Development Economics 74: 199-250.

Skoufias, E. and Susan W. Parker (2001); Conditional Cash Transfers and their Impact on Child Work and Schooling: Evidence from the PROGRESA program in Mexico. Economia, 2(1):45-96.

White, H. (1980); A heteroskedasticity-consistent covariance matrix and a direct test for heteroskedasticity. Econometrica 48: 817-38.

Windmeijer, F. (2005); A finite sample correction for the variance of linear efficient two-step GMM estimators. Journal of Econometrics 126: 25-51

Yanchus, D. and X. de Vanssay (2003); The Myth of Fair Prices: A graphical analysis. Journal of Economic Education. 34(3):235-240. 


\section{Table 1: Description of variables used}

\begin{tabular}{ll}
\hline \hline Variable & Description \\
Male & DV equal to 1 if the respondent is male \\
Age & Age in years \\
Education & Years of school attended \\
Education mother & Education of the mother in years \\
Education father & Education of the father in years \\
Children & Number of children \\
Income total & Actual total income realized last year \\
Income honey & Income from honey last year \\
Income bees & Income from other bees' products last year \\
Honey production & Total production of honey in kilos \\
Productivity per hour & Prodution of honey per hour worked \\
& DV (dummy variable) equal to 1 if the respondent is \\
directly associated to FT cooperatives & DV equal to 1 if the respondent is only indirectly \\
Flo & associated to FT cooperatives \\
Half Flo & DV equal to 1 if the respondentis not associated to FT \\
& cooperatives \\
No Flo & Number of affiliation years \\
FT age & \\
\hline \hline
\end{tabular}

\section{Table 2: Descriptive statistics}

\begin{tabular}{lllllllll}
\hline \hline Variable & Obs & Mean & Std. Dev. & Min & $\mathbf{Q} * \mathbf{1}$ & $\mathbf{Q * 2}$ & $\mathbf{Q * 3}$ & Max \\
\hline Male & & & & & & & & \\
Age & 234 & 0.84 & 0.37 & 0 & 1 & 1 & 1 & 1 \\
Education & 234 & 49.74 & 12.70 & 24 & 40 & 50 & 59 & 88 \\
Education mother & 233 & 9.92 & 4.19 & 0 & 7 & 10 & 12 & 22 \\
Education father & 224 & 4.56 & 4.01 & 0 & 1 & 4 & 6 & 16 \\
Children & 224 & 4.66 & 4.27 & 0 & 1 & 4 & 6 & 18 \\
Income total & 231 & 2.50 & 1.89 & 0 & 1 & 2 & 4 & 11 \\
Income honey & 231 & $4,988,680$ & $11,400,000$ & 0 & $1,015,000$ & $2,500,000$ & $5,000,000$ & $110,000,000$ \\
Income bees & 229 & $2,109,031$ & $3,878,463$ & 0 & 300,000 & $1,000,000$ & $2,350,000$ & $40,000,000$ \\
Honey production & 230 & 346,100 & $1,016,250$ & 0 & 0 & 0 & 50,000 & $10,000,000$ \\
Productivity per hour & 225 & 3,232 & 6,134 & 0 & 300 & 1,000 & 3,000 & 60,000 \\
Flo & 224 & 180 & 306 & 0 & 36 & 78 & 200 & 3,333 \\
Half Flo & 234 & 0.46 & 0.50 & 0 & 0 & 0 & 1 & 1 \\
No Flo & 234 & 0.12 & 0.33 & 0 & 0 & 0 & 0 & 1 \\
FT age & 234 & 0.42 & 0.49 & 0 & 0 & 0 & 1 & 1 \\
& 137 & 6.90 & 5.36 & 0 & 3 & 3 & 10 & 25 \\
\hline \hline
\end{tabular}

*Quantile 


\section{Table 3: Distribution of affiliated producers by FT age}

\begin{tabular}{cccc}
\hline \hline Affiliation years & Observations & Percent & Cumulative \\
\hline 1 & 14 & 10.77 & 10.77 \\
2 & 13 & 10.00 & 20.77 \\
3 & 20 & 15.38 & 36.15 \\
4 & 10 & 7.69 & 43.85 \\
5 & 9 & 6.92 & 50.77 \\
6 & 7 & 5.38 & 56.15 \\
7 & 2 & 1.54 & 57.69 \\
8 & 8 & 6.15 & 63.85 \\
9 & 2 & 1.54 & 65.38 \\
10 & 19 & 14.62 & 80.00 \\
11 & 2 & 1.54 & 81.54 \\
12 & 7 & 5.38 & 86.92 \\
14 & 3 & 2.31 & 89.23 \\
15 & 4 & 3.08 & 92.31 \\
16 & 1 & 0.77 & 93.08 \\
18 & 2 & 1.54 & 94.62 \\
20 & 6 & 4.62 & 99.23 \\
25 & 1 & 0.77 & 100.00 \\
\hline Total & 130 & 100 & 100 \\
\hline \hline
\end{tabular}

\section{Table 4: Education level by number of affiliation years}

\begin{tabular}{lccccccc}
\hline \hline Aff.Years & $\mathbf{2 0 0 7}$ & $\mathbf{2 0 0 6}$ & $\mathbf{2 0 0 5}$ & $\mathbf{2 0 0 4}$ & $\mathbf{2 0 0 3}$ & $\mathbf{2 0 0 2}$ & $\mathbf{2 0 0 1}$ \\
\hline \multicolumn{7}{l}{ Education of the producer } \\
& & & & & & & \\
$1-3$ & 10.40 & 10.45 & 10.43 & 10.44 & 10.37 & 10.38 & 10.15 \\
$4-6$ & 10.38 & 9.52 & 9.58 & 8.37 & 8.60 & 8.11 & 8.62 \\
$7-9$ & 8.37 & 8.60 & 8.11 & 8.42 & 6.77 & 6.00 & 6.50 \\
$10-12$ & 8.62 & 6.77 & 6.00 & 6.50 & 6.80 & 7.66 & 6.50 \\
& & & & & & & \\
\hline \hline Aff.Years & $\mathbf{2 0 0 7}$ & $\mathbf{2 0 0 6}$ & $\mathbf{2 0 0 5}$ & $\mathbf{2 0 0 4}$ & $\mathbf{2 0 0 3}$ & $\mathbf{2 0 0 2}$ & $\mathbf{2 0 0 1}$ \\
\hline
\end{tabular}

Education of the producer's father

$\begin{array}{llllllll}1-3 & 5.33 & 5.18 & 5.21 & 5.18 & 5.11 & 5.10 & 4.89 \\ 4-6 & 3.94 & 4.41 & 3.58 & 3.77 & 3.23 & 2.89 & 2.88 \\ 7-9 & 3.17 & 3.26 & 2.89 & 2.88 & 1.80 & 2.14 & 2.37 \\ 10-12 & 2.89 & 1.80 & 2.14 & 2.37 & 3.20 & 3.00 & 2.50\end{array}$

\begin{tabular}{llllllll}
\hline \hline Aff.Years & 2007 & 2006 & 2005 & 2004 & 2003 & 2002 & 2001 \\
\hline
\end{tabular}

Education of the producer's mother

$\begin{array}{llllllll}1-3 & 5.16 & 5.09 & 5.04 & 5.04 & 4.96 & 4.98 & 4.80 \\ 4-6 & 4.00 & 3.70 & 4.16 & 3.39 & 3.50 & 2.62 & 2.88 \\ 7-9 & 3.39 & 3.05 & 2.62 & 1.88 & 1.50 & 2.71 & 1.87 \\ 10-12 & 1.88 & 1.50 & 2.71 & 2.87 & 3.40 & 4.00 & 4.00\end{array}$




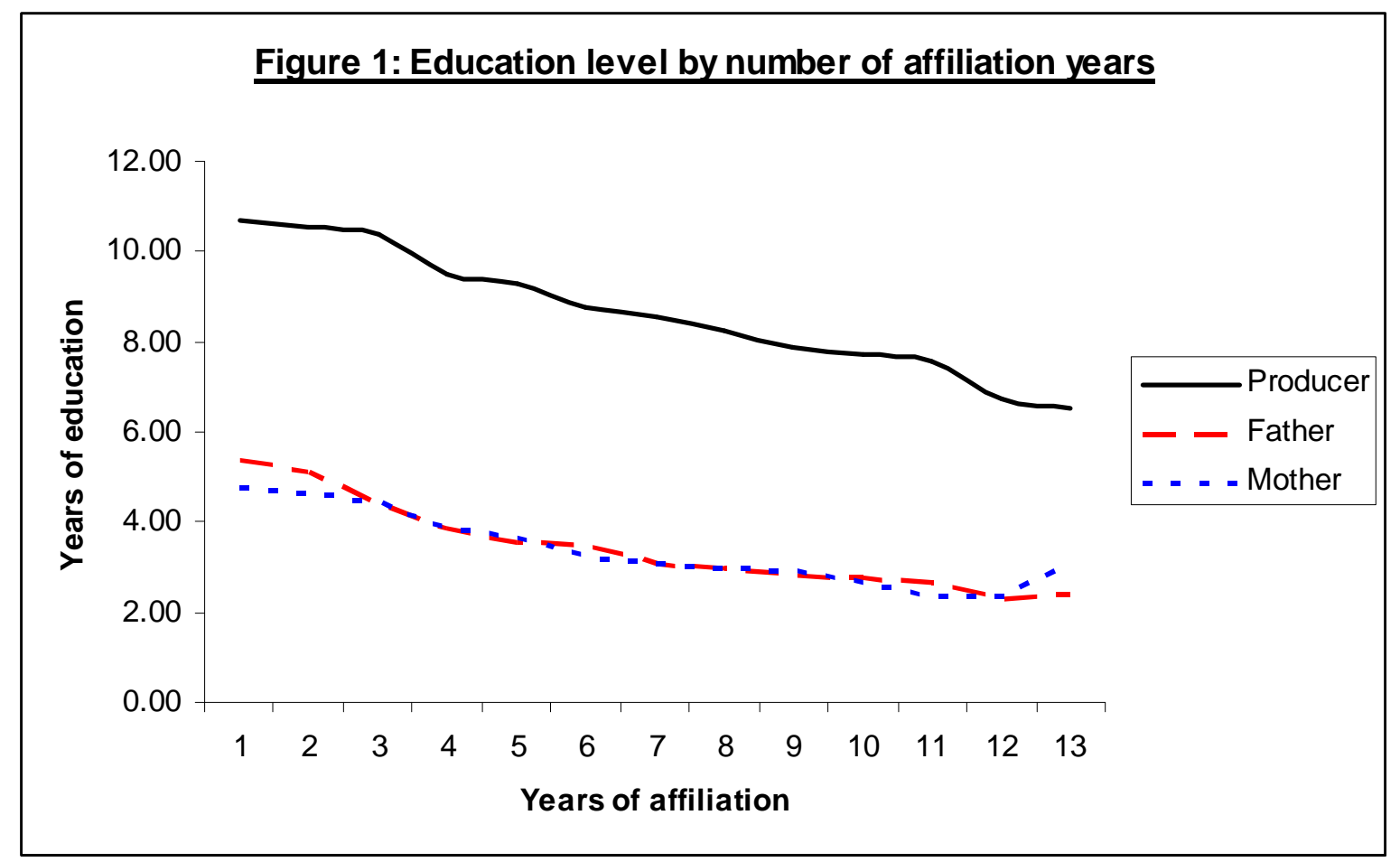

Note: Figures refer to averages over the period 2001-2007 


\section{Table 5.1 Fixed effects model over the full sample}

\begin{tabular}{lccccc}
\hline \hline \multicolumn{7}{c}{ HIS 10-18 } & HIS 11-18 & HIS 12-18 & HIS 13-18 & HIS 14-18 \\
\hline Tot. Pot. & -0.030962 & -0.0311771 & -0.0299827 & -0.0212994 & -0.0185246 \\
& $(-3.33)$ & $(-2.87)$ & $(-2.31)$ & $(-1.32)$ & $(-0.93)$ \\
Age & -0.0273542 & -0.0248527 & -0.0213023 & -0.0199538 & -0.017313 \\
& $(-10.45)$ & $(-8.50)$ & $(-6.43)$ & $(-5.39)$ & $(-4.16)$ \\
FT Age & 0.0095477 & 0.0126911 & 0.0148914 & 0.0158515 & 0.0181 \\
& $(2.29)$ & $(2.70)$ & $(2.81)$ & $(2.57)$ & $(2.56)$ \\
& & & & & \\
\hline & & & & & \\
$N$ & 1.823 & 1.691 & 1.544 & 1.388 & 1.222 \\
Nr. of Groups & 165 & 165 & 160 & 151 & 148 \\
$\mathrm{R}^{2}$ within & 0.1303 & 0.1130 & 0.0996 & 0.0943 & 0.0931 \\
$\mathrm{R}^{2}$ between & 0.0444 & 0.0416 & 0.0416 & 0.0266 & 0.0180 \\
$\mathrm{R}^{2}$ overall & 0.0545 & 0.0506 & 0.0423 & 0.0322 & 0.0286 \\
F1(overall & 11.68 & 9.13 & 7.18 & 6.03 & 5.15 \\
goodness of fit) & $(0.00)$ & $(0.00)$ & $(0.00)$ & $(0.00)$ & $(0.00)$ \\
F2 (significance & 7.31 & 7.11 & 7.21 & 6.92 & 6.62 \\
of fixed effects) & $(0.00)$ & $(0.00)$ & $(0.00)$ & $(0.00)$ & $(0.00)$ \\
& & & & & \\
\hline \hline
\end{tabular}

\section{Table 5.2 Fixed effects model (treatment group only)}

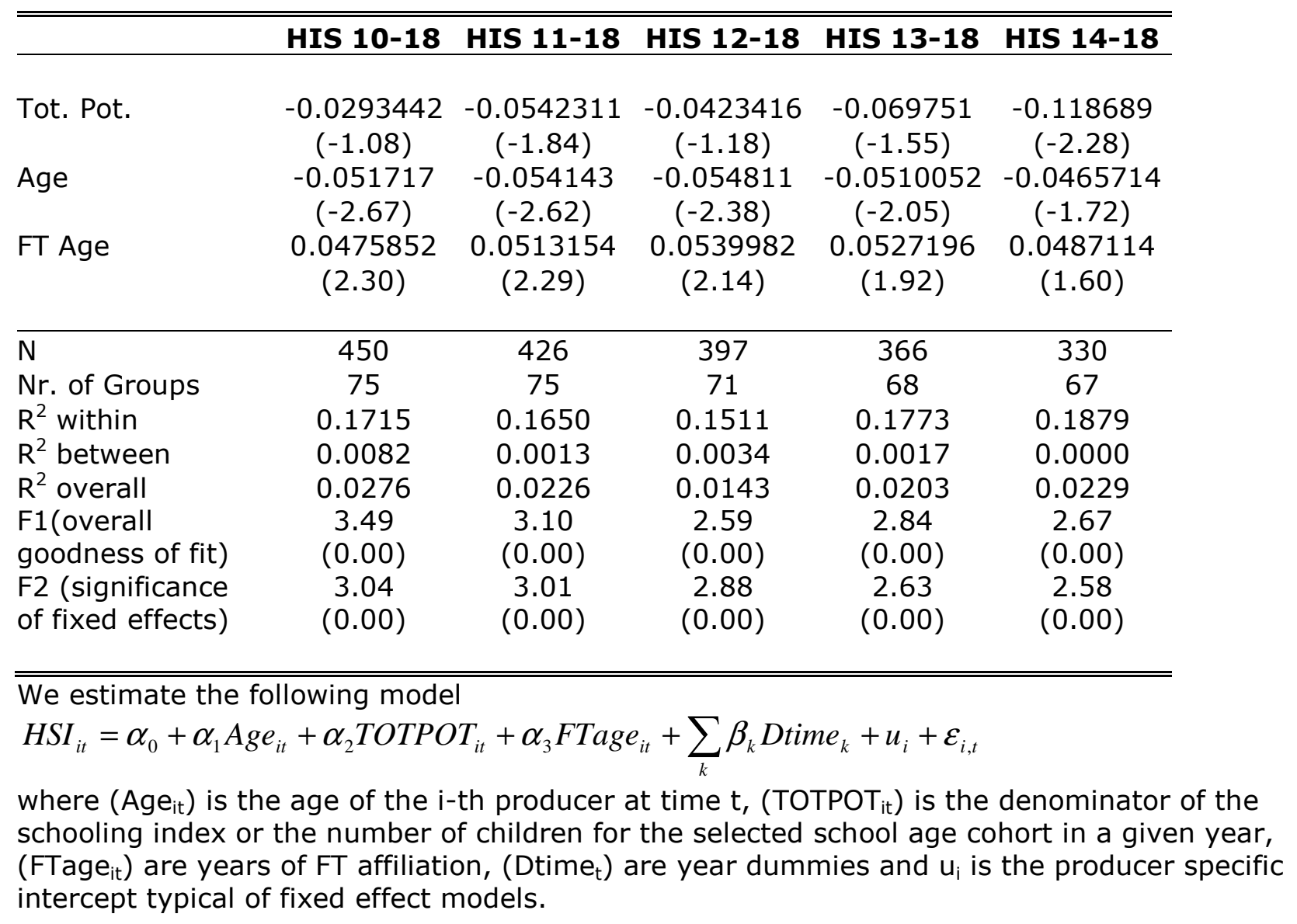


Table 6.2 Robustness check: GMM estimates on the effects of FT affiliation on the Household Schooling Index (treatment and control group)

\begin{tabular}{|c|c|c|c|c|c|}
\hline & $\begin{array}{c}\text { 10-18 SCHOOL AGE } \\
\text { COHORT }\end{array}$ & 11-18 SCHOOL AGE COHORT & 12-18 SCHOOL AGE COHORT & 13-18 SCHOOL AGE COHORT & 14-18 SCHOOL AGE COHORT \\
\hline \multirow[t]{2}{*}{$\mathbf{H S I}_{\mathbf{i}, \mathrm{t}-1}$} & .349 & .227 & .0636 & -.0476 & .2813 \\
\hline & $(2.05)$ & $(1.39)$ & $(0.28)$ & $(-0.24)$ & $(1.18)$ \\
\hline \multirow[t]{2}{*}{ Ftage $_{i, t-1}$} & .009 & .012 & .0164 & .0180 & .0124 \\
\hline & $(4.05)$ & $(4.41)$ & $(5.89)$ & $(5.40)$ & $(3.02)$ \\
\hline \multirow[t]{2}{*}{ ТОТРОТ } & .047 & .0361 & .0847 & 1.302 & -.0766 \\
\hline & $(0.92)$ & $(0.70)$ & $(1.50)$ & $(1.78)$ & $(-1.81)$ \\
\hline \multirow[t]{2}{*}{ Schoolyear } & .0451 & .0768 & .119 & 0.116 & .1447 \\
\hline & $(2.12)$ & $(3.56)$ & $(4.56)$ & $(3.91)$ & $(4.41)$ \\
\hline \multirow[t]{2}{*}{ Age } & .0092 & -.027 & -.0371 & -.049 & -.0345 \\
\hline & $(4.05)$ & $(4.42)$ & $(5.86)$ & $(-5.86)$ & $(-3.16)$ \\
\hline Number of obs. & 1521 & 1398 & 1259 & 1116 & 1100 \\
\hline \multirow[t]{2}{*}{$\mathrm{AR}(1)$ test } & 3.73 & -3.25 & -1.82 & -2.02 & -2.01 \\
\hline & $(0.00)$ & $(0.001)$ & $(0.07)$ & $(0.043)$ & $(0.04)$ \\
\hline \multirow[t]{2}{*}{$\mathrm{AR}(2)$ test } & 1.03 & 0.68 & -0.61 & -0.26 & 0.65 \\
\hline & $(0.30)$ & $(0.49)$ & $(0.54)$ & $(0.793)$ & $(0.51)$ \\
\hline \multirow[t]{2}{*}{ Sargan test } & 38.50 & 53.01 & 60.18 & 65.76 & 62.44 \\
\hline & $(0.742)$ & $(0.193)$ & $(0.06)$ & $(0.03)$ & $(0.05)$ \\
\hline Test on common pre- & -.034 & -.008 & -.011 & .0022 & .0006 \\
\hline affiliation trends* & $(-3.56)$ & $(-0.99)$ & $(-1.51)$ & $(0.31)$ & $(0.09)$ \\
\hline Davidson-McKinnon & .0091 & .0747 & 1.92 & .886 & .5511 \\
\hline exogeneity test & $(0.924)$ & $(.784)$ & $(0.09)$ & $(0.346)$ & $(.458)$ \\
\hline Wald (20) & 470.81 & 416.45 & 448.03 & 379.73 & 388.65 \\
\hline Prob $>\chi 2$ & $(0.00)$ & $(0.00)$ & $(0.00)$ & $(0.00)$ & $(0.00)$ \\
\hline
\end{tabular}

The base specification is: $\operatorname{HSI}\left(\tau_{k}, \tau_{l}\right)_{i, t}=\alpha_{0}+\alpha_{1} \operatorname{HSI}\left(\tau_{k}, \tau_{l}\right)_{i, t-1}+\alpha_{2}$ Age $_{i, t-1}+\alpha_{3} \operatorname{Totpot}_{2}\left(\tau_{k}, \tau_{l}\right)_{i, t-1}+\alpha_{4} F_{t a g} e_{i, t-1}+\sum_{k} \beta_{k} \operatorname{Dtime} e_{k}+\varepsilon_{i, t}$

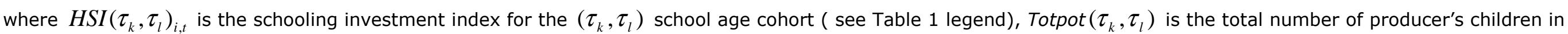

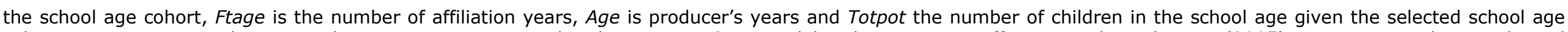

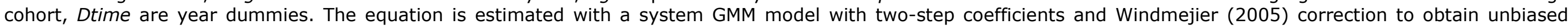

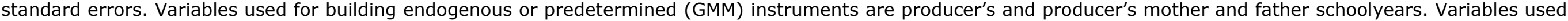

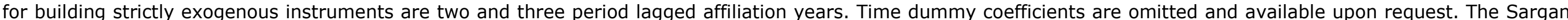

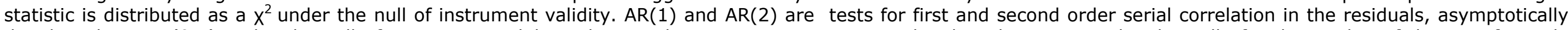

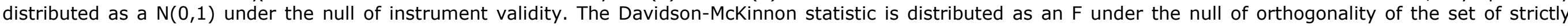

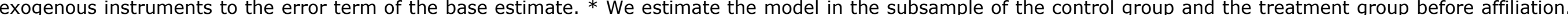

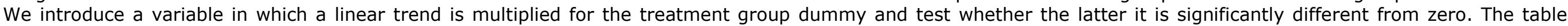
report the coefficient and the t-statistics. 
Table 6.3 Robustness check: GMM estimates on the effects of FT affiliation on the Household Schooling Index (treatment group only)

\begin{tabular}{|c|c|c|c|c|c|}
\hline $\mathbf{H S I}_{\mathbf{i}, \mathrm{t}-\mathbf{1}}$ & $\begin{array}{c}.330 \\
(1.89)\end{array}$ & $\begin{array}{c}.078 \\
(0.49)\end{array}$ & $\begin{array}{c}.295 \\
(1.50)\end{array}$ & $\begin{array}{c}.273 \\
(1.32)\end{array}$ & $\begin{array}{c}.367 \\
(1.85)\end{array}$ \\
\hline Ftage $_{i, t-1}$ & $\begin{array}{c}.005 \\
(1.79)\end{array}$ & $\begin{array}{c}.007 \\
(2.41)\end{array}$ & $\begin{array}{c}.080 \\
(2.12)\end{array}$ & $\begin{array}{c}.004 \\
(1.05)\end{array}$ & $\begin{array}{c}.002 \\
(1.46)\end{array}$ \\
\hline ТОТРОТ & $\begin{array}{c}.088 \\
(1.46)\end{array}$ & $\begin{array}{c}.093 \\
(1.65)\end{array}$ & $\begin{array}{l}1.143 \\
(1.64)\end{array}$ & $\begin{array}{c}.068 \\
(0.89)\end{array}$ & $\begin{array}{l}.048 \\
(0.52) \\
.154\end{array}$ \\
\hline Schoolyear & $\begin{array}{c}.110 \\
(3.14)\end{array}$ & $\begin{array}{l}.0768 \\
(3.56)\end{array}$ & $\begin{array}{c}.170 \\
(4.15)\end{array}$ & $\begin{array}{l}0.201 \\
(4.54)\end{array}$ & $(3.26)$ \\
\hline Age & $\begin{array}{c}.0076 \\
(0.62) \\
\end{array}$ & $\begin{array}{c}.023 \\
(2.20) \\
\end{array}$ & $\begin{array}{r}.0111 \\
(0.82) \\
\end{array}$ & $\begin{array}{c}-.049 \\
(-5.86) \\
\end{array}$ & $\begin{array}{c}.020 \\
(1.45) \\
\end{array}$ \\
\hline Number of obs. & 408 & 379 & 353 & 316 & 274 \\
\hline $\mathrm{AR}(1)$ test & $\begin{array}{l}-3.98 \\
(0.00)\end{array}$ & $\begin{array}{c}-2.82 \\
(0.005)\end{array}$ & $\begin{array}{l}-3.34 \\
(0.01)\end{array}$ & $\begin{array}{l}-3.66 \\
(0.00)\end{array}$ & $\begin{array}{l}-4.15 \\
(0.04)\end{array}$ \\
\hline $\operatorname{AR}(2)$ test & $\begin{array}{c}0.78 \\
(0.43)\end{array}$ & $\begin{array}{l}-0.43 \\
(6.69)\end{array}$ & $\begin{array}{c}0.72 \\
(4.74)\end{array}$ & $\begin{array}{c}1.44 \\
(1.49)\end{array}$ & $\begin{array}{c}1.58 \\
(0.115)\end{array}$ \\
\hline Sargan test & $\begin{array}{c}54.05 \\
(0.167)\end{array}$ & $\begin{array}{l}80.48 \\
(0.01)\end{array}$ & $\begin{array}{l}60.18 \\
(0.06)\end{array}$ & $\begin{array}{l}55.76 \\
(0.18)\end{array}$ & $\begin{array}{l}54.04 \\
(0.16)\end{array}$ \\
\hline $\begin{array}{l}\text { Test on common pre- } \\
\text { affiliation trends (young } \\
\text { affiliated)* }\end{array}$ & $\begin{array}{c}-.035 \\
(-3.73)\end{array}$ & $\begin{array}{c}-.007 \\
(-0.95)\end{array}$ & $\begin{array}{c}-.0112 \\
(-1.555)\end{array}$ & $\begin{array}{c}.003 \\
(0.47)\end{array}$ & $\begin{array}{c}.004 \\
(0.61)\end{array}$ \\
\hline $\begin{array}{l}\text { Test on common pre- } \\
\text { affiliation trends (old } \\
\text { affiliated)* } \\
\text { Davidson-McKinnon } \\
\text { exogeneity test } \\
\text { Wald (20) } \\
\text { Prob }>\boldsymbol{\chi 2}\end{array}$ & $\begin{array}{c}.010 \\
(0.33) \\
.0384 \\
(0.844) \\
134.12 \\
(0.00)\end{array}$ & $\begin{array}{c}.032 \\
(1.02) \\
.320 \\
(.572) \\
416.45 \\
(0.00)\end{array}$ & $\begin{array}{c}.036 \\
(1.37) \\
.1274 \\
(0.7213) \\
125.72 \\
(0.00)\end{array}$ & $\begin{array}{c}.0435 \\
(1.74) \\
.568 \\
(0.451) \\
124.39 \\
(0.00)\end{array}$ & $\begin{array}{c}.0501 \\
(1.44) \\
.2286 \\
(.6331) \\
79.55 \\
(0.00)\end{array}$ \\
\hline
\end{tabular}

We estimate the model in the subsample of the control group and the treatment group before affiliation. We introduce a variable in which a linear trend is multiplied for the treatment group dummy and test whether the latter it is significantly different from zero. The table reports the coefficient and the t-statistics. For the legend see Table 6.2. 